This item was submitted to Loughborough's Research Repository by the author.

Items in Figshare are protected by copyright, with all rights reserved, unless otherwise indicated.

\title{
Do prices grow more in Euro-land? Evidence from the airline industry
}

PLEASE CITE THE PUBLISHED VERSION

LICENCE

CC BY-NC-ND 4.0

\section{REPOSITORY RECORD}

Bachis, Enrico, and Claudio Piga. 2019. "Do Prices Grow More in Euro-land? Evidence from the Airline Industry". figshare. https://hdl.handle.net/2134/1284. 
This item was submitted to Loughborough's Institutional Repository by the author and is made available under the following Creative Commons Licence conditions.

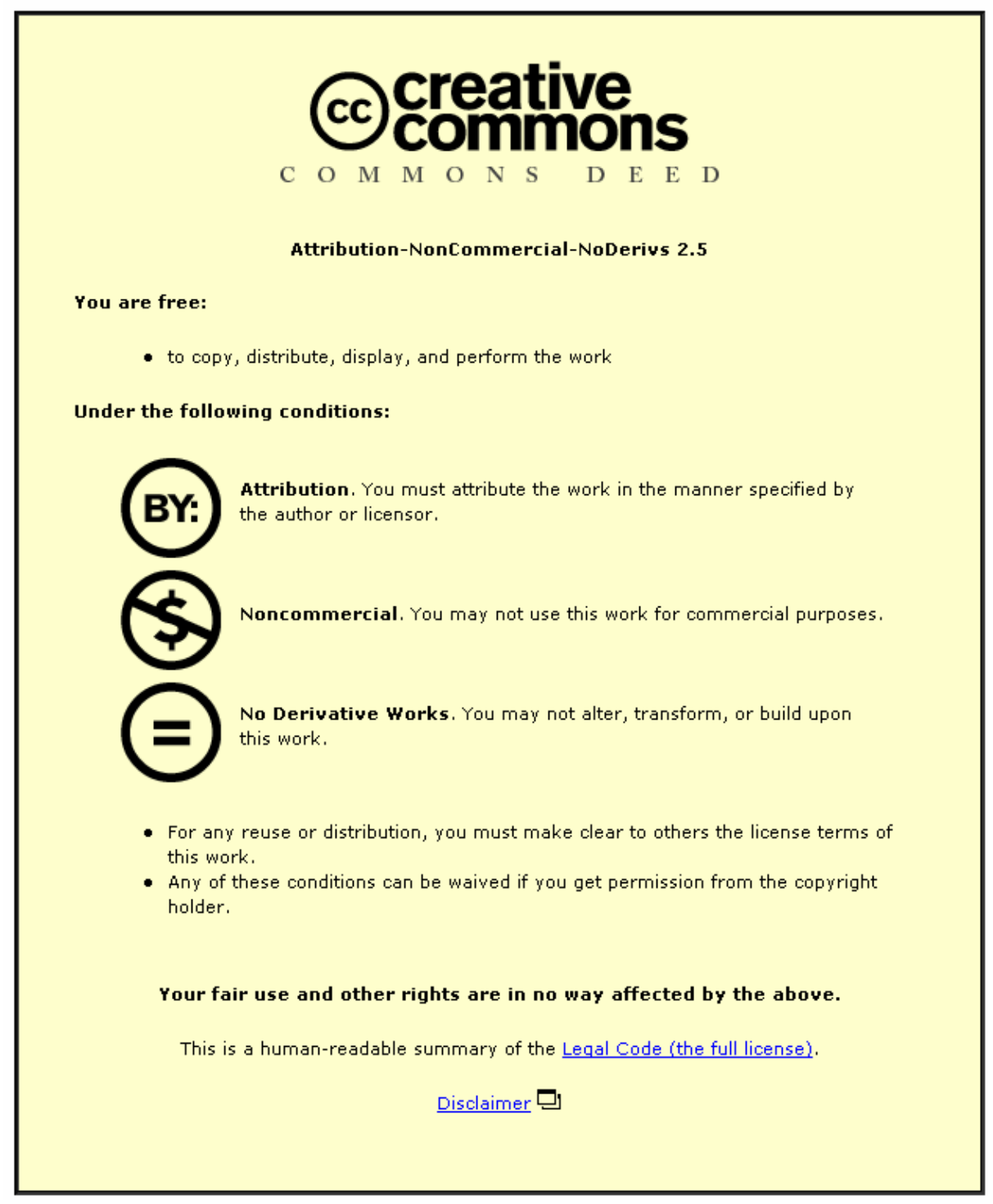

For the full text of this licence, please go to: http://creativecommons.org/licenses/by-nc-nd/2.5/ 


\title{
Do prices grow more in Euro-land? Evidence from the airline industry
}

\author{
Enrico Bachis \\ Nottingham University Business \\ School \\ lizeb@gwmail.nottingham.ac.uk
}

\author{
Claudio Piga* \\ Economics Department, \\ Loughborough University \\ c.a.g.piga@lboro.ac.uk
}

March 2006

\begin{abstract}
Using more than 10 million on-line fares, we study the determinants of yearly fares' changes in June 2002-June 2005. We verify whether airlines took advantage, after the Euro introduction, of potential inflationary pressures by increasing their fares more in routes to Eurozone nations. The evidence suggests that this was the case only for the period end 2003-end 2004. To control for other factors that may affect fares' setting decisions, we provide insights into the effects of the takeovers of Go Fly and Buzz by EasyJet and Ryan Air, respectively. Although we generally find that fares offered immediately after the takeover by the acquiring firms were lower than the ones charged by the target firms twelve months earlier, in one case the effects of the takeover on consumers' welfare are ambiguous.
\end{abstract}

JEL classification: L11, L13, L93

Keywords: Price discrimination; takeovers, Euro, changeover.

\footnotetext{
*Contact Author. Address for correspondence: Economics Department, Loughborough University, Leicestershire, UK, LE11 3TU, Tel: +44 (0) 1509 222755; Fax: (+44)-(0) 1509 223910. Piga gratefully acknowledges receipt of the British Academy Larger Research Grant LRG-35378. This paper was presented at the 2005 EARIE conference in Porto, at the 2006 International Industrial Organization Society in Boston and at the 2006 Royal Economic Society Conference in Nottingham, as well at a seminar in Newcastle. The authors are grateful for the comments received. Thanks to Theo Panagiotidis for his feedback. The usual disclaimer applies.
} 


\section{Introduction}

"[...] the European Commission has announced it will investigate allegations that Apple is unfairly charging up to 20 per cent more for music downloads in the UK than it does in the rest of Europe. Apple charges UK users about $83 p$ a track compared with about $52 p$ in France and Germany. Apple says its pricing was based on "the underlying economic model in each country".

Financial Times, $4^{\text {th }}$ March 2005

As Motta (2003) posits: "price discrimination is a pervasive phenomenon, of which examples from our daily life abound" (p.491). A recent example is given by the differential pricing made by Apple in the electronic music market. Similarly, a visit to the web site of Tele2, the international telecommunication company, will reveal that it charges 12.5 eurocent per minute (plus a fixed charge of 15.5 eurocent at the conversation start) for calls from Italy to UK, while residents in UK pay their calls to Italy only 2.5 pence per minute (and no fixed charge at the start). ${ }^{1}$ At the current exchange rate of $0.7 £$ /euro, this corresponds to a situation where the Italian residents are charged about four times more.

A company's ability to charge different prices for the same product in different countries is an instance of "third degree price discrimination" (Motta, 2003). Two recent developments have brought back the issue of price discrimination to the forefront of economic analysis. Firstly, the Internet was considered a technological advancement capable of bringing about a business environment replicating the characteristics of a perfectly competitive market i.e. low search costs, low barriers to entry and easy price comparability. However, doubts were immediately cast on the likelihood that the Internet would engender "frictionless markets" (Ellison and Ellison, 2005).

Secondly, on the $1^{\text {st }}$ of January 2002, twelve European countries adopted a common currency, the Euro. It was expected that its introduction could enhance transparency of prices, facilitate comparisons across countries and, ultimately, competition. Contrary to these predictions, anecdotal evidence reported on the press seems to suggest a huge rise in the price level after the Euro changeover. This was particularly severe in sectors protected by international competition. More formally, Baye et al (2005) compare on-line electronic goods before and after the changeover, and find that average and minimum prices increased, respectively, by $3 \%$ and $7 \%$. In the case of the European car market, Goldberg and Verboven

1 Information retrieved from the site $\underline{w w w . t e l e 2 . i t}$ on March, $14^{\text {th }} 2006$. and from www.tele2.co.uk before Tele2's UK operations were sold to another company in January 2006. 
(2004) concluded that price differentials in Eurozone countries decreased after the Euro introduction, but that cross-country price differences remained large, even among members. They argue that the remaining high price differentials after the euro call for structural interventions.

Interestingly, a structural approach such as the liberalisation of the European Civil Aviation industry was fully completed in 1997. Since then, a frantic entry and exit activity has taken place, leading to the establishment of many new carriers adopting the "low-cost" business concept pioneered in the U.S. by the Southwest Airline (Boguslaski et al., 2004, Gil-Molto and Piga, 2005).

It is against this backdrop that we aim to study the determinants of annual price changes in the airline industry over the period June 2002- June 2005. To do so, we rely on primary data obtained by retrieving the fares posted on-line for flights within UK, and from UK to other European countries. The annual price changes are worked out to remove seasonality, for the same company operating on a given route. After controlling for variations in cost, inflation, exchange rate and market structure, we attempt to shed light on three issues.

First, we focus on whether the airlines systematically increased their fares more to take advantage of the turmoil following the Euro adoption, especially in the second half of 2003 and in the first part of 2004. Thus, given our period of analysis, we do not compare fares pre- and post-changeover but we provide some evidence of its consequences. The comparison of each country with the base case of UK reveals that fares evolved very similarly for flights to both UK domestic and each of main Eurozone countries' destinations. However, Eurozone countries as a whole, compared to those outside Eurozone, recorded higher increases in the period Apr 2004Mar 2005 (relative to the previous corresponding 12 months). Such a difference was short-lived, as no significant difference is found in the subsequent period, and is generally restricted to certain fare categories.

Second, our analysis reveals important insights into the effects of the takeovers of Go Fly and Buzz by EasyJet and Ryan Air, respectively, which occurred in the period under study. Generally, it was found that the acquiring firms reduced their fares relative to the levels charged 12 months earlier by the target firms. Thus, in the months following the takeover Easyjet reduced its fares by about $16 \%$, while Ryan Air by 7\%. However, an important distinction needs to be emphasized. The findings indicate that the Easyjet reductions were found across all fares available from 70 days up to 1 day prior to departure. In contrast, Ryan Air offered higher average late booking fares (those for purchases made less than 7 days before departure) while it also cut its early booking ones. These findings indicate that in the aviation industry, the 
evaluation of a merger in terms of its benefit for consumers should take into account the variety of fares that airlines offer.

Third, we estimate the magnitude of the promotional fares offered by low cost carriers (henceforth, LCC) when they enter a new route. When the analysis is disaggregated between early booking and late booking fares, the estimates reveal an increase in fares of about $11 \%$ twelve months after a new service is launched. These differences become negligible when fares across different booking periods are averaged out, suggesting how post-entry promotional pricing tends to be associated mostly with certain categories of fares, presumably those for early bookings.

The paper is organized as follows. The next section illustrates how the fares were collected, and the nature of the secondary data used to describe the traffic on a route. Section 3 provides some descriptive statistics derived from the original price dataset, plus information on the estimation strategy. Section 4 outlines the econometric models, whose results are commented in the Section 5. Some conclusive remarks are included in Section 6.

\section{Data Collection}

Most of the empirical contributions on pricing behaviour in the Civil Aviation industry have focused, so far, mainly on the U.S. market, whereas few studies have been devoted to the European market. Moreover, the analysis of the U.S. aviation sector has been mostly conducted relying on different cohorts of the same dataset, namely the Databank of the U.S.A. Department of Transportation's Origin and Destination Survey, which is a 10 percent yearly random sample of all tickets that originate in the United States on U.S. carriers (Evans and Kessides, 1993; Borenstein and Rose, 1994; Hayes and Ross, 1998; Alam et al., 2001; Stavins, 2001; Liu, 2003). In this dataset prices are measured as one-way fares and are computed as one-half of the reported fare round-trip tickets. All tickets other than one-way and round trips are excluded.

In contrast, our analysis is based on primary data on fares and secondary data on routes traffic. Initially, when the project began in May 2002, fares were collected using an " electronic spider", which connected directly to the websites of only the main LCC (i.e., Ryanair, Buzz, Easyjet, GoFly) operating in Britain at the time. Collection of fares for flights operated by Full Service Carriers (i.e., British Airways, Air Lingus, Air France, Lufthansa, KLM, Alitalia, Iberia, SAS, Tap Portugal, Air Europa and Maersk) started in March 2003: in this case, fares were collected only for flights that Full Service Carriers (henceforth, FSC) operated on routes similar 
or identical to those where a LCC also flew. ${ }^{2}$ This decision was necessary to reduce the number of routes under study, where each route is identified in this study as an airport pair combination.

The dataset includes daily flights information operated from June 2002 up to, and including, June 2005, for a total of 37 months. Over the period of analysis, a number of important events took place which are somehow reflected in the dataset. First, a series of takeovers occurred: Easyjet acquired GoFly (December 2002) and Ryan Air took over Buzz (March 2003). Second, new LCC began their operations: the "spider" was upgraded to retrieve fares from the Bmibaby and MyTravelLite sites. However, due to technical difficulties, fares from Flybe, which was already an established LCC, and Thomson Fly, a new entrant could not be obtained. This is not important, as far as sample selection issues are concerned, as traffic operated by every airline is used to construct market indicators.

Over the 37 months period, fares from UK for flights to and from the following Euroadopting countries were obtained: Austria, Belgium, France, Germany, Greece, Ireland, Italy, Netherlands, Portugal and Spain. A term of comparison is provided by fares for flights to the following countries outside the Euro area: Czech Republic, Norway, Sweden, Switzerland as well as UK, whose domestic routes were also considered.

In order to account for the variety of fares offered by airlines at different times prior to departure, every day we collected the fares for departures due, respectively, 1, 4, 7, 10, 14, 21, $28,35,42,49,56,63$ and 70 days from the date of the query. Henceforth, these will be referred to as "booking days". So, for instance, if we consider London Stansted-Rome Ciampino as the route of interest, and assume the query for the flights operated by a given airline was carried out on March $1^{\text {st }} 2004$, the spider would retrieve the prices for both the London Stansted-Rome Ciampino and the Rome Ciampino-London Stansted routes for departures on 2/3/04, 5/3/04, $8 / 3 / 04,11 / 3 / 04$ and so on. The return flight for both types of journeys was scheduled one week after the departure. For those routes where an airline operates more than one flight per day, all fares for every flight were collected. Thus, for every daily flight we managed to obtain up to 13 prices that differ by the time interval from the day of departure. The main reason to do so was to satisfy the need to identify the evolution of fares - from more than two months prior to departure to the day before departure - which has been noted to be very variable for the case of LCC (Pels and Rietveld, 2004; Giaume and Guillou, 2004). While the spider could have retrieved any

${ }^{2}$ The airfares of the traditional companies were collected from the website www.opodo.co.uk, which is owned and managed by British Airways, Air France, Alitalia, Iberia, KLM, Lufthansa, Aer Lingus, Austrian Airlines, Finnair and the global distribution system Amadeus. Thus, fares listed on Opodo are the official prices of each airline, although Opodo may not report promotional offers that each airline may offer on their web sites. 
number of prices, in practice the need to reduce both the number of queries made to an airline server and the time of programme execution to a manageable level, led to the design above. Furthermore, given the site characteristics of Opodo, it was impossible to collect Full Service Carriers' fares 1 and 4 days prior to departure: it was also decided to omit collecting fares from these companies for flights due to depart more than 49 days after the query. Thus, for Full Service Carriers, up to 8 fares per daily flight are available.

The collection of the airfares has been carried out everyday at the same time: in addition to airfares we collected the name of the company, the time and date of the query, the departure date, the scheduled departure and arrival time, the origin and destination airports and the flight identification code.

Fares were collected before tax and handling fees for the case of LCC, but inclusive of them for the Full Service Carriers (henceforth FSC). This is not a problem for two reasons. First, as discussed below, the analysis focuses on the changes made by each airline on the fares posted in the same months of two consecutive years. Thus, differencing would generally cancel out the taxes included in the FSC' fares. Second, while airport taxes were increased over the three years period we consider, these changes were of negligible magnitude $(2-5 \%)$ and occurred in the great majority of destinations. Furthermore, fares for LCC were one-way, while those for FSC were for a round trip and were therefore halved.

To complement the price data with market structure characteristics, secondary data on the traffic for all the routes and all the airlines flying to the countries indicated above was obtained from the UK Civil Aviation Authority (henceforth, CAA). ${ }^{3}$ For each combination of company, route and departure period (i.e., month/year), the CAA provided the number of monthly seats, the number of monthly passengers and the monthly load factors. These were broken down at the flight identification code level, that is, for each flight each airline operated in a given month on a route. However, in order to create a more balanced panel, fares and traffic statistics were aggregated at the route level for each airline, thereby not exploiting the detailed information available at the flight code level.

Figure 1 provides a summary of the evolution of total flights and passengers' traffic from the UK to the universe of destinations in the Euro and no Euro areas (the latter including UK domestic flights). Some striking aspects emerge. First, the six main LCC considered in this study operate about a third of flights to both areas: evidence not reported suggests that Ryan Air and EasyJet manage a large share of these flights, especially after the two takeovers. A similar

\footnotetext{
${ }^{3}$ See www.caa.co.uk
} 
comment can be made with regards to passengers' traffic. Second, LCC seem to benefit from higher load factors, as their Total Passengers curve remains above that of Total Flights. ${ }^{4}$ In contrast, the FSC' Total Passengers curve is always well below the corresponding Total Flights' one. Finally, traffic to Eurozone destinations tends to be influenced more by seasonal fluctuations.

\section{Estimation strategy and Datasets Analysis}

Two reduced-form models are estimated. The first is formally represented as follows:

$$
\Delta_{12} \ln \left(P_{i j b t}\right)=X_{1 j t}^{\prime} \beta_{1}+X_{2 i j t}^{\prime} \beta_{2}+X_{3 i t}^{\prime} \beta_{3}+Z_{1 j}^{\prime} \gamma_{1}+Z_{2 i}^{\prime} \gamma_{2}+Z_{3 b}^{\prime} \gamma_{3}+\delta_{i j b}+\varepsilon_{i j b t}
$$

where $P$ is the mean price for each $i j b$ group over a month, $\mathrm{i}=$ company; $\mathrm{j}=$ route (and therefore country of arrival); $b=$ booking days to departure; $t=$ month. Regressors may be time variant (the $X \mathrm{~s}$ ) and invariant (the $Z \mathrm{~s}$ ), while the errors are given by the sum of an unobserved effect (the $\delta$ ) and an idiosyncratic component (the $\varepsilon$ ). For each month, average fares for an airline on a given route were calculated by using all the fares' observations in each "booking days" group. Then, to obtain the dependent variable, we computed the percentage change of these average fares in the same months of two consecutive years. Such a strategy enables us to compare "likes" with "likes" to deal with the presence of seasonal fluctuations and to identify whether airlines tended to increase their fares differentially across "booking days".

The second approach aggregates over "booking days" and therefore considers the change of an average price, which is the result of the different fares available at different points in time. That is:

$$
\Delta_{12} \ln \left(P_{i j t}\right)=X_{1 j t}^{\prime} \beta_{1}+X_{2 i j t}^{\prime} \beta_{2}+X_{3 i t}^{\prime} \beta_{3}+Z_{1 j}^{\prime} \gamma_{1}+Z_{2 i}^{\prime} \gamma_{2}+\delta_{i j}+\varepsilon_{i j t}
$$

Comparisons between the estimates from (1) and (2) are assumed to yield interesting insights into the impact of the variety of fares offered by airlines. The following analysis of some of the datasets' features is relevant for both models.

Table 1 reports average one-way fares by the airlines in different seasons (corresponding to the Summer - April to October- and the Winter - November to March timetables). Note how more than 10 millions daily fares were used to calculate the monthly averages for each group. About $70 \%$ of these observations pertain to flights operated by EasyJet and Ryan Air. The two main British FSC are also highly represented: British Airways with

\footnotetext{
${ }^{4}$ The number of total passengers was divided by 100 , so that the same scale could be used to represent both types of curves.
} 
about 1 million observation and BMI British Midland with almost half a million, to which one should add the observations of its low-cost subsidiary, BmiBaby. In any case, routes offered by the FSC were selected only for those markets (identified by city pairs, e.g., London to Rome) where at least one LCC was operating. Thus, Table 1 offers a straightforward way to compare fares by competing companies in differentiated markets. Generally, even accounting for the obvious difference due to the inclusion of airport taxes in the FSC' fares, the latter seem to be higher throughout the period.

Table 2 shows yearly changes for the mean, median and minimum price in each month, broken down by area of destination and "booking days". A first point is the greater fluctuation of the minimum fares, suggesting that these may be often used to gauge demand. Another noteworthy distinction regards how late booking fares ( 1 to 4 days to departure) have generally increased throughout the period, while the largest variations are shown for fares retrieved 35 up to 14 days prior to departure. This may be indicative of a more intense competition triggered by the airlines' interest to maximise load factors. Relatedly, fares remained relatively stable when they were posted 10 up to 7 days to departure. Table 2 does not show any indication of larger increases in Eurozone. A further analysis of the evolution of fare changes by country and type of carrier is provided in Figure A1 and A2 in Appendix A.

Table 3 reports statistics on the number of routes that are served, respectively, by one, two and three or more companies, where the number of airlines is worked out using the CAA data. Three different samples are used. The universe of routes is indicated in the CAA column: throughout the period, about $77 \%$ of total routes are monopoly, $18 \%$ or more are duopolies and about $5 \%$ or less have three or more players. This is a clear indication of an industry in which companies try to avoid direct competition by exploiting the possibility to serve a city pair (say London-Rome) by using different routes that are part of that city pair (e.g., Heathrow-Rome Fiumicino and London Stansted-Rome Ciampino).

In Table 3, the Internet columns outline the number of routes for which we have fares information in our Internet-retrieved dataset. It clearly shows that overall we have retrieved fares for about one third of the universe of routes (up to 283 in June 2005 from a universe of 774). These differences are most likely due to the way routes for FSC were chosen, given that we left out routes where FSC do not face direct or indirect competition by LCC. Relative to the universe, monopoly routes tend to be marginally under-represented, while duopolistic routes in particular are over-represented. This is also a reflection of the way the FSC' routes were selected. 
In Table 3, the Estimation columns differ from the Internet price ones for two reasons. First, to calculate the monthly mean we considered only groups (i.e., a combination of airlineroute-booking day) where we had at least 11 observations per group per month. This is to avoid a spurious measure of the monthly average obtained from a very limited number of days or flights. Second, a route may have been added at later stage and so it was not possible to work out the twelve months' lag difference. Nonetheless, the percentages in the Estimation columns do not differ drastically from those obtained from the CAA data. Furthermore, the estimation sample was intended to mostly represent routes where LCC operate, as well as routes and markets where LCC and FSC compete with each other. This is why the Estimation sample generally represents about $40.0 \%$ of the universe of duopoly routes and $50 \%$ or more of the universe of routes with 3 or more players.

\section{The empirical model}

In this section, we first describe the variables used to estimate equations (1) and (2). In the following discussion we distinguish the time-variant regressors as being route, company and company-route specific.

\section{Route-specific regressors.}

Potential country-level determinants of the annual change in the airline prices are represented by the inflation and the exchange rate of the euro and the other European currencies with respect to the British pound. The variable "Inflation Rate" is expected to exert a positive influence on the annual fare changes, as it represents a broad measure of the price dynamics within each country. It is also interacted with the "Eurozone" dummy, which is equal to one for every Euro adopting countries.

Table 4 shows a differing behaviour for the Sterling exchange rate: it depreciated in the first two periods while remaining generally stable afterwards. Thus, we interact the exchange rate yearly variation in each country with the seasonal dummies to obtain two variables: " $\% \Delta$ Exchng rate Seas $3 / 4$ " and "\% $\Delta$ Exchng rate Seas 5/6/7". The economic rationale for their inclusion is two-fold. Firstly, an appreciation of the European currencies with respect to the sterling pound may imply higher costs for goods and services denominated in European currencies. Secondly, there exists a more compelling, demand-side hypothesis. An appreciation of the continental Europe currencies should make travelling to UK cheaper for continental Europe's residents, and more expensive for British travellers. Thus, a fare increase is simply likely not to influence the former's decision to travel, as the holiday costs are reduced thanks to the currency's appreciation. Given this situation, it would be sensible for airlines to increase 
fares following a continental Europe's currency appreciation. On the other hand, such an attempt to extract more surplus from continental Europeans may reduce the traffic of British travellers. These opponent forces should therefore neutralize the expected effect of variations in the exchange rate, if we assume that price elasticities are identical between these two groups of travellers. However, since the majority of route served by LCC can be considered, to a great extent, tourist destinations and given the documented short run inelasticity of the British tourist demand towards European countries ( $\mathrm{Li}$ et al. 2003), we expect a negative coefficient and, therefore, a positive contributions in terms of the annual change in the posted airfares.

Over the last three seasons in Table 4, jet-fuel prices have increased at a rate well above $35 \%$, relative to the same months a year earlier. This has certainly had strong repercussions on the fare settings. To this purpose, we have collected the Rotterdam (ARA) Kerosene-Type Jet Fuel Spot Price from the U.S. Department of Energy's web site. ${ }^{5}$ However, the consumption of fuel varies with the different phases of the flight: when the aircraft flies at cruising speed fuel consumption is much lower than when the airplane takes off or lands. Thus, in order to capture these economies of scale we include the route distance in miles

"City-pair Size", obtained as the share of total flights in a city pair over the total flights to a country, provides an index of a market size and its potential demand. The "Route HHI" is the HHI index obtained by summing the squares of the market shares of the airlines in a route, where market shares are obtained in terms of number of flights each airline offers in a month. Both these variables identify a market structure characteristic and are therefore potentially endogenous with the decision to set fares. However, the number of flights an airline offers is decided a season in advance, when timetables are prepared. Fares are set in a more flexible way and can be adapted to reflect intervening circumstances. Thus the number of flights is likely to influence fares, but not be influenced by them. In other words, it is unlikely that both "City-pair Size" and "Route HHI" are correlated with the idiosyncratic errors $\varepsilon_{t}$. It is on the other hand possible that they are correlated with the unobserved effect $\delta_{i j}$ : e.g., where airlines can charge higher fares they will also increase their capacity. Such considerations have important implications for our econometric approach.

Company specific regressors. To capture the consequences on fares changes due to the takeovers discussed in the Introduction, the difference in the LHS of equations (1) and (2) is taken between the mean monthly fare charged by the target firm (Go Fly or Buzz) at month $t$

\footnotetext{
${ }^{5}$ Because these were reported in USD cents per gallon, before calculating the annual changes, the prices were converted using the euro/dollar exchange rate from Datastream.
} 
and the mean monthly fare charged by the acquiring firm (EasyJet or Ryan Air) at $(t+12)$. The dummies "D_Buzz 1 yr post takeover" and "D_Gofly 1 yr post takeover" identify such observations. The estimated signs indicate whether the acquiring firms charged more or less relative to the target firms and therefore provide an indication as to whether the takeovers were welfare improving or reducing, at least in the aftermath of the takeovers. However, to control for long term effects, the observations for the price changes in the second year after the takeovers were also identified by two dummies: "D_Buzz 2 yrs post takeover" and "D_Gofly 2 yrs post takeover".

Company-route specific regressors. The number of UK departure airports that an airline uses to serve a given destination (variable " $N$ departures airline to arrival"), and the number of routes an airline serves within a city pair (variable " $N$ routes airline in citypair") are aimed at assessing if an airline's network influences its fares' setting.

The dummy "D_Own Entry in route" indicates the twelfth month (and the subsequent two) after an airline enters a new route. Thus we try to capture the magnitude of the promotional fares an airline offers when launching a new service, by ascertaining whether and by how much fares have increased a year after entry. The dates of entry were obtained from the CAA dataset using the first period an airline is recorded on a route. A similar approach was followed in Gil Molto and Piga (2005) for the study of entry and exit in European routes and Berry (1992) for the case of entries in U.S. routes.

Finally, we identify the two most important UK airports for each airline . To obtain this, we consider the total number of flights each airline operates from every UK airport. A dummy was used to identify the two most important (variable "D_Departure is a hub"). Note that such a variable is time invariant, at least in our dataset where the airlines exhibit a tendency to occupy a dominant position in certain airports. ${ }^{6}$ Again, a potential endogeneity with respect to the unobserved effect is assumed.

Dummy regressors. In order to control for seasonal fluctuations, we introduced the five dummy variables Jun03-Oct03, Nov03-Mar04, Apr.04-Oct04, Nov04-Mar05 and Apr05-Jun05, where the first constitutes the base period. These are also interacted with the dummy "Eurozone" to capture common trends among the countries in the common currency area.

${ }^{6}$ E.g., London Stansted and Glasgow Prestwick are the two most used UK airports by Ryan Air, Stansted and London Luton by EasyJet. Generally, the hubs thus defined correspond to the expectation an industry expert might have. For British Airways, the two hubs are, not surprisingly, Heathrow and Gatwick. 
Country dummies were also included to assess potential systematic differences among countries that may complement the fact of being or not being member of the Euro area. These are of paramount relevance in the evaluation of the impact of the Euro introduction, as structural characteristics of an individual member country's economy may have exacerbated or facilitated the post-changeover transition.

"Booking days" effects were taken into account by allowing the following values for $b$ in the $i j b$ groups in equation (1): $1-4 ; 7-10 ; 14-21 ; 28-35 ; 42-49 ; 56-70$. These numbers represent the number of days prior to departure the fares were retrieved. For each of these values a dummy variable was constructed, the first being the base case. Furthermore, a dummy for each airline is included.

Table 4 reports a list of some of the time variant regressors described above, as well as the data sources. Across periods, the inflation rates were marginally lower in the Euro area relative to the average of the countries in the sample. The average number of departure airports used by an airline to serve a destination has increased from 2.8 in the first period to 4.6 in the last, thereby suggesting a tendency to reduce bureaucratic costs at the destination level by exploiting economies of scale (Berry, 1992). In contrast, the number of routes an airline serves within a city pair tended to remain stable. The airlines in our sample entered new routes mostly during the period November 03 - March 05. As one would expect in a liberalised industry, the mean value of the HHI in our sampled routes declined throughout the periods. Finally, about two-thirds of the observations pertain to flights departing from a UK airport deemed as a hub.

\section{The estimation methods}

In equations (1) and (2), many explanatory variables are time invariant. Unfortunately, in a fixed-effects model, these variables are not identified. Using a random-effects model is not appropriate in our case, where some of the regressors are potentially correlated with the unobserved effects. To obtain coefficients for the time-invariant explanatory variables in (1) and (2), we rely on two methods.

First, Hausman and Taylor (1981) propose an Instrumental Variable (IV), random effects (RE) estimator in which some of the explanatory variables are correlated with the unobserved effects, but not with the idiosyncratic error.

The second method is a two-stage FE estimation procedure for the consistent estimation of the coefficients on the time invariant regressors, developed in Polachek and Kim (1994) and 
further studied in Oaxaca and Geisler (2003). ${ }^{7}$ Recently, Bilotkach (2006) has applied it in a study of price dispersion in the U.S. airline market.

The two-stage FE estimation procedure operates in the following manner:

- Estimate each of our models by FE to obtain the $\beta_{\mathrm{k}}{ }^{\mathrm{FE}}, \mathrm{k}=1 . .3$.

- Use these to estimate a heteroskedastic-robust OLS

$$
\Delta_{12} \ln \left(P_{i j b} \bullet\right)-X_{K}^{\prime} \cdot \beta_{k}^{F E}=Z_{1 j}^{\prime} \gamma_{1}+Z_{2 i}^{\prime} \gamma_{2}+Z_{3 b}^{\prime} \gamma_{3}+\delta_{i j b}+\varepsilon_{i j b},
$$

where $\Delta_{12} \ln \left(P_{i j b \bullet}\right)$ and $X_{K}$. are the group means of the time variant dependent and explanatory variables. Note how, given the potential endogeneity of some of the $Z \mathrm{~s}$, the second stage has to employ an IV procedure.

Initially the first stage was also estimated using an IV approach, assuming that the "Route HHI" could be endogenously correlated with the idiosyncratic error. A Hausman's test rejected such hypothesis. The first stage FE estimates are obtained using heteroskedastic and panel autocorrelation-consistent variance estimates.

\section{Results}

The results from the estimation of equations (1) and (2) are reported in Tables 5 and 6, respectively. To account for possible biases induced by the different methods used to collect the data for FSC, the Tables include both estimates from the full sample (FSC + LCC) and the LCC sample only. Generally, similar implications could be drawn, so the following discussion is based on the full sample's results.

First, note how the time-varying coefficients from the IV RE procedure tend to be similar to those obtained using the two-stage FE approach, thus suggesting the correlation of "Citypair Size", "route HHI" and "D_Departure is a Hub" with the unobserved effect. ${ }^{8}$ As far as the time-invariant regressors are concerned, the two methods estimate coefficients that have similar magnitudes, signs and level of significance. Thus, the two methods lead to equivalent conclusions, which will be discussed by focussing on the possible differential effects in Euro-

${ }^{7}$ Oaxaca and Geisler (2003) demonstrate the equivalence between the two-stage FE GLS estimates and the OLS coefficient estimates from a pooled cross-section, time -series model. However, because the estimated standard errors differ, they derive a test to discriminate between the two methods. However, given the potential endogeneity of some explanatory variables with the unobserved effects, we will employ only the two-stage FE estimator.

${ }^{8}$ It is not possible to produce a formal Hausman test given the differences in which the standard errors are computed in the two methods, Similarly, no AIC can be obtained after the coefficients' computations, which led to the choice of showing the results from both methods. 
adopting countries, the post-takeovers pricing behaviour of the acquiring firms, and the postentry pricing behaviour of an entrant. A brief comment on the remaining control variables is made at the end of this section.

\subsection{Did fares grow more in the Eurozone?}

Relative to the base-period, the seasonal dummies reveal a growing trend for fares: in Table 5, Eurozone fares in seasons 5 and 6 increased more than average by $5-7 \%$. Such an effect maintains its magnitude but loses its significance in Table 6 , suggesting that the higher increases in Table 5 may be due to variability induced by the airlines' yield management techniques and have little to do with international price discrimination. Relative to the UK base-case, in Table 5 the countries' dummies are generally insignificant or negative, with the exception of Spain and France in the LCC sample. These effects disappear in Table 6, where the dummies for Eurozone countries become largely insignificant in most cases, or negative. This is again consistent with an attempt by airlines to use differential fares across booking periods to maximise revenues and manage volatile levels of demand, and lends little support to the hypothesis of systematic price discrimination across countries.

Recall how the exchange rate is assumed to affect the cost for airlines of goods and services denominated in currencies other than the sterling as well as a traveller's total cost of a trip. In periods 3 and 4, a 1\% appreciation of the Euro relative to the sterling is associated with an increase of about $0.7 \%$ in fares. In subsequent periods, when the sterling remained more stable, no significant correlation is found in Table 5, although Table 6 indicates that an appreciation of the sterling by $1 \%$ was accompanied by an increase of about $0.5 \%$. Thus, in line with Goldberg and Verboven (2004), we find that differences in prices may be induced by differences in the monetary policies inside and outside the Eurozone.

Further support in this sense is provided by the coefficients of the inflation rate in Table 5: while outside the Eurozone the elasticity of fares with respect to inflation is about 4.6, in Eurozone the changes in inflation rates are negatively associated with fare changes. However, such a difference seems to be driven by specific yield management techniques whose effects cancel out when the fares across different booking periods are averaged out. Indeed, the net impact of the inflation rate changes in Table 6 is very close to zero for the Eurozone members.

\subsection{Price changes resulting from the takeovers.}

Table 5 shows how, in the twelve month following the takeovers, EasyJet reduced its fares by $16 \%$ on the same routes where Gofly was operative, while Ryan Air charged on 
average 7\% less than Buzz. However, two important distinctions can be inferred regarding the pricing behaviour of the acquiring firms. First, the above reductions by Ryan Air in the first year disappear in Table 6, while they are confirmed in the Gofly case. To further investigate this finding, Figure 3 reports the percentage change of pre-takeover fares relative to the posttakeover ones, broken down by booking period. It is evident that EasyJet reduced its fares across all booking periods. On the contrary, Ryan Air only reduced its early booking fares but sharply increased late booking fares. Thus, in the short term, whether the Ryan Air/Buzz takeover has produced beneficial effects depends crucially on the proportion of early booking passengers (e.g., those travelling on tourism or to visit friends and relatives) relative to late booking customers (i.e., people travelling on business). Although we do not have data on sales made at different times prior to departure, it is unlikely that a large proportion of seats are sold only a few days prior to departure, especially considering the large price hikes imposed by airlines in these circumstances.

However, further doubts on the benefits of the Ryan Air takeover are shown in the two Tables 5 and 6. Indeed, Ryan Air, in its second year of operation on the routes previously serviced by Buzz, pushed its fares up by about 10\%: this time, no difference arises in the two Tables, indicating that the increases were consistent across the booking periods. In shark contrast, EasyJet did not raise its fares relative to the level it charged immediately after the takeover. Bearing in mind that this analysis does not consider possible cost-saving effects for the acquiring firm, and given the low fares reported in Table 1, it is unlikely that the Buzz takeover could be deemed welfare reducing. Our results, however, reveal how in the aviation industry, the evaluation of a merger in terms of its benefits for consumers should take into account the variety of fares that airlines offer.

\subsection{Promotional fares and other control variables}

The coefficient for "D_Own Entry in a route" in Table 5 reveals how the entrants charged on average $11 \%$ more twelve months after the entry in a new route. This could be explained by promotional pricing aimed at making the new service known to potentially interested travellers. When early booking fares are averaged with late booking ones, as in Table 6 , post-entry fares appear to be only marginally positive and significant. Thus, promotional pricing seems to be available only for certain categories of fares, presumably those for early booking.

Elasticity of fare changes relative to fuel cost is about 0.39 : as expected, fares reflect cost variations, although this may have differential impact across airlines, as some of them may 
have signed up from long-term contract with fuel suppliers and may be therefore less affected by the steep upward trend of oil price. The negative sign of the "Distance" variable reflects possible economies of scale arising from the fixed costs due to landing and take-off.

On average, fares in routes departing from an airline's hub increased 13\% less than in routes where the departure airport is not a hub. This seems in contrast with previous studies revealing a "hub premium" arising from the exploitation of the strategic advantages that hubs conferred to U.S. airlines (Borenstein, 1989). However, the negative coefficient suggests how the principal reason why most European LCC arrange as many flights as possible from a limited number of departure airports is to save on overhead costs (Berry, 1992).

Finally, the measures for market size and route concentration point out to larger fare rises in denser markets and in more concentrated routes. There are consistent across the two Tables.

\section{Conclusions}

Our empirical analysis shows that third-degree price discrimination has not exerted any strong impact on the annual changes of the on-line airfares within the European civil aviation market. That is, we find little evidence that airlines set their fares by systematically using "the underlying economic model in each country", as in the case of Apple. Indeed, difference among countries seem to be driven mainly by the contingent state of demand in relation to the number of days that separate the date in which a fare is posted from the date a flight departs. However, as discussed in Goldberg and Verboven (2004), monetary policy in Eurozone, by affecting the dynamics of exchange rates and inflation, seems to have repercussions on airlines' pricing.

Our findings indicate uncontroversial positive welfare-effects for the EasyJet/Go Fly takeover and reveal interesting insights on the practice of fares' setting by Ryan Air, at least as far as the routes it took over from Buzz are concerned. Indeed, relative to Buzz, Ryan Air raised its late booking fares, but reduced the fares available 21 days or earlier prior to departure. This is perfectly consistent with the standard textbook treatment of third-degree price discrimination where consumers with less elastic demands are charged more. More generally, the evidence indicates how the evaluation of mergers in the aviation market should take into account the array of fares offered by airlines at different points in time.

Similarly, promotional pricing is more likely to be offered only for certain categories of fares: this has obvious implications on how to assess the impact of a new entrant (Joskow et al., 1994). 


\section{References}

Alam, Ila M. S., Leola B. Ross and Robin C. Sickles. (2001). 'Time Series Analysis of Strategic Behaviour in the US Airline Industry', Journal of Productivity Analysis 16, 49-2.

Baye, Michael R., Rupert Gatti, Paul Kattuman, and John Morgan. (2005). 'Did the Euro foster on-line competition? Evidence from an International Price Comparison site', Economic Enquiry, forthcoming.

Bilotkach, Volodymyr, 2006, Understanding Price Dispersion in the Airline Industry: Capacity Constraints and Consumer Heterogeneity, in Lee, Darin (ed), Advances in Airline Economics. Competition Policy and Antitrust, Elsevier, Amsterdam.

Boguslaski, C., Ito, H. and D. Lee, 2004, Entry Patterns in the Southwest Airlines Route System, Review of Industrial Organization, 25, pp. 317-350.

Borenstein, Severin, 1989, Hubs and High Fares: Airport Dominance and Market Power in the U.S. Airline Industry, Rand Journal of Economics, 20, pp.344-365.

Borenstein, Severin, and Nancy L. Rose. (1994). 'Competition and Price Dispersion in the U.S Airline Industry', Journal of Political Economy 102, 653-683.

Ellison, Glenn, and Sara F. Ellison, 2005, Lessons about Markets from the Internet, Journal of Economic Perspectives, 19(2), Spring, 139-158.

Evans, William N., and Ioannis N. Kessides, 1993, 'Localized Market Power in the U.S. Airline Industry', Review of Economics and Statistics 75 (1), 66-75.

Giaume, Stephanie, and Sarah Guillou. (2004). Price Discrimination and Concentration in European Airline Market, Journal of Air Transport and Management 10(5), 293-370.

Gil-Molto, Maria J. and Claudio A. Piga, 2005, Entry and Exit in a Liberalised Market, Discussion Paper Series, N. 2005_10, Economics Dept. Loughborough University.

Goldberg, Pinelopi K., and Frank Verboven. (2004). EU car prices, Economic Policy, 19(40), 484-521.

Hayes, Kathy J., and Leola B. Ross. (1998). 'Is Airline Price Dispersion the Result of Careful Planning or Competitive Forces?' Review of Industrial Organization 13, 523-541.

Joskow, A.S., Werden, G.J. and R.L. Johnson, 1994, Entry, Exit and Performance in Airline Markets, International Journal of Industrial Organization, 12, 457-471. 
Li, Gang, Haiyan Song, and Stephen F. Witt. (2004). Modelling Tourism Demand: A Dynamic Linear AIDS Approach, Journal of Travel Research 43(2), 141-150.

Liu, Qihong. (2003). 'The Effect of Market Structure on Price Dispersion: An Analysis of the U:S. Airline Industry', April 2003, SUNY Stony Brook.

Motta, Massimo. Competition Policy. Theory and Practice. Cambridge University Press, 2003.

Oaxaca, Ronald L. and Iris Geisler (2003), Fixed effects models with time invariant variables: a theoretical note, Economics Letters, 80, 373-377.

Pels, Eric, and Piet Rietveld. (2004). 'Airline pricing behaviour in the London-Paris market', Journal of Air Transport Management 10, 279-283.

Polachek, Solomon W. and Moon-Kak Kim (1994), Panel estimates of the gender earnings gap: individual-specific intercept and individual-specific slope models, Journal of Econometrics, 61, 23-42.

Stavins, Joanna. (2001). 'Price Discrimination in the Airline Market: The Effect of Market Concentration', The Review of Economics and Statistics 83 (1), 200-202. 


\section{Appendix A.}

Figure A1: Average Monthly Price \% change in Eurozone countries by type of carrier.
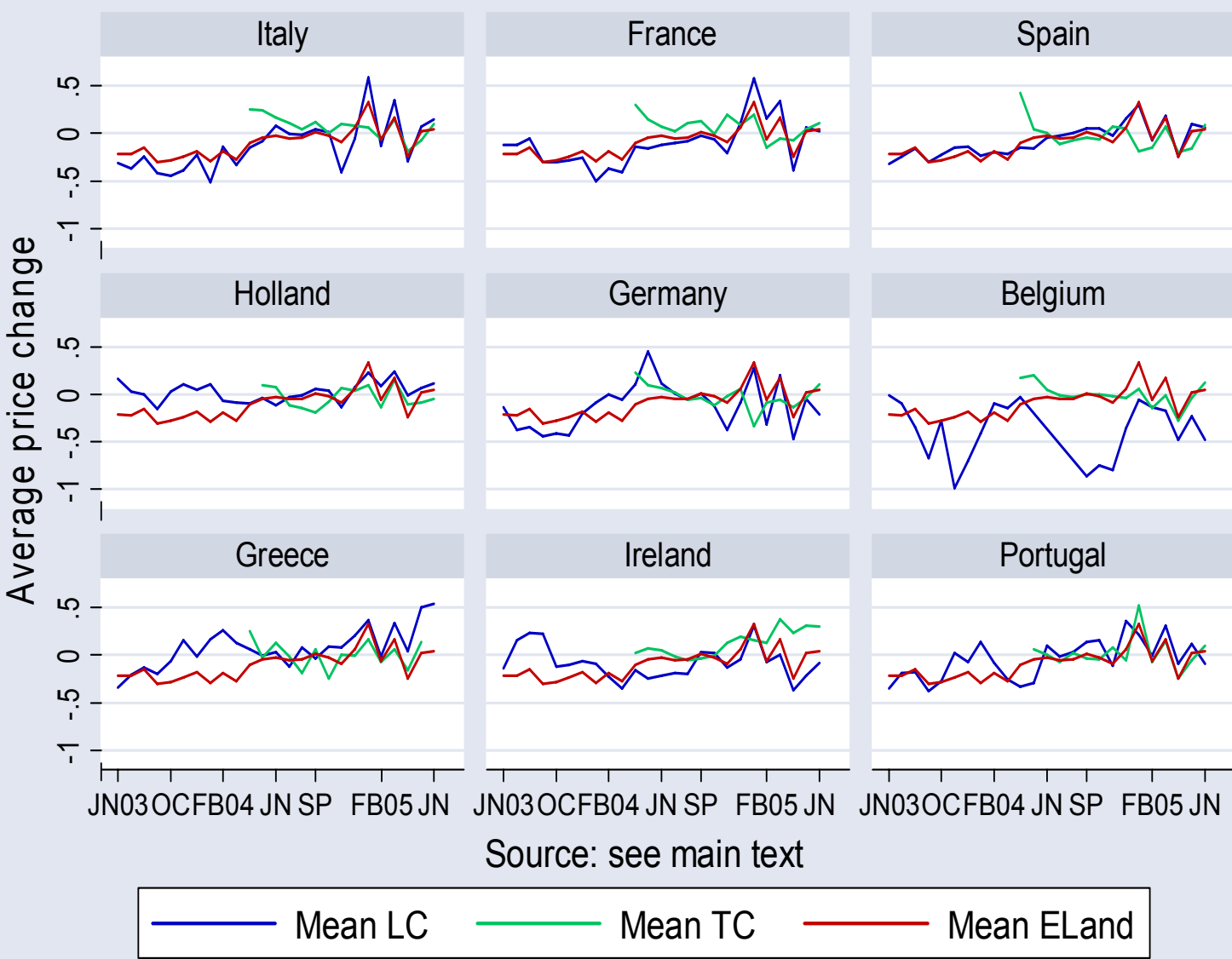

Graphs by nation_euro

Source: our Internet-retrieved fares. 
Figure A2: Average Monthly Price \% change in non-Eurozone countries by type of carrier.
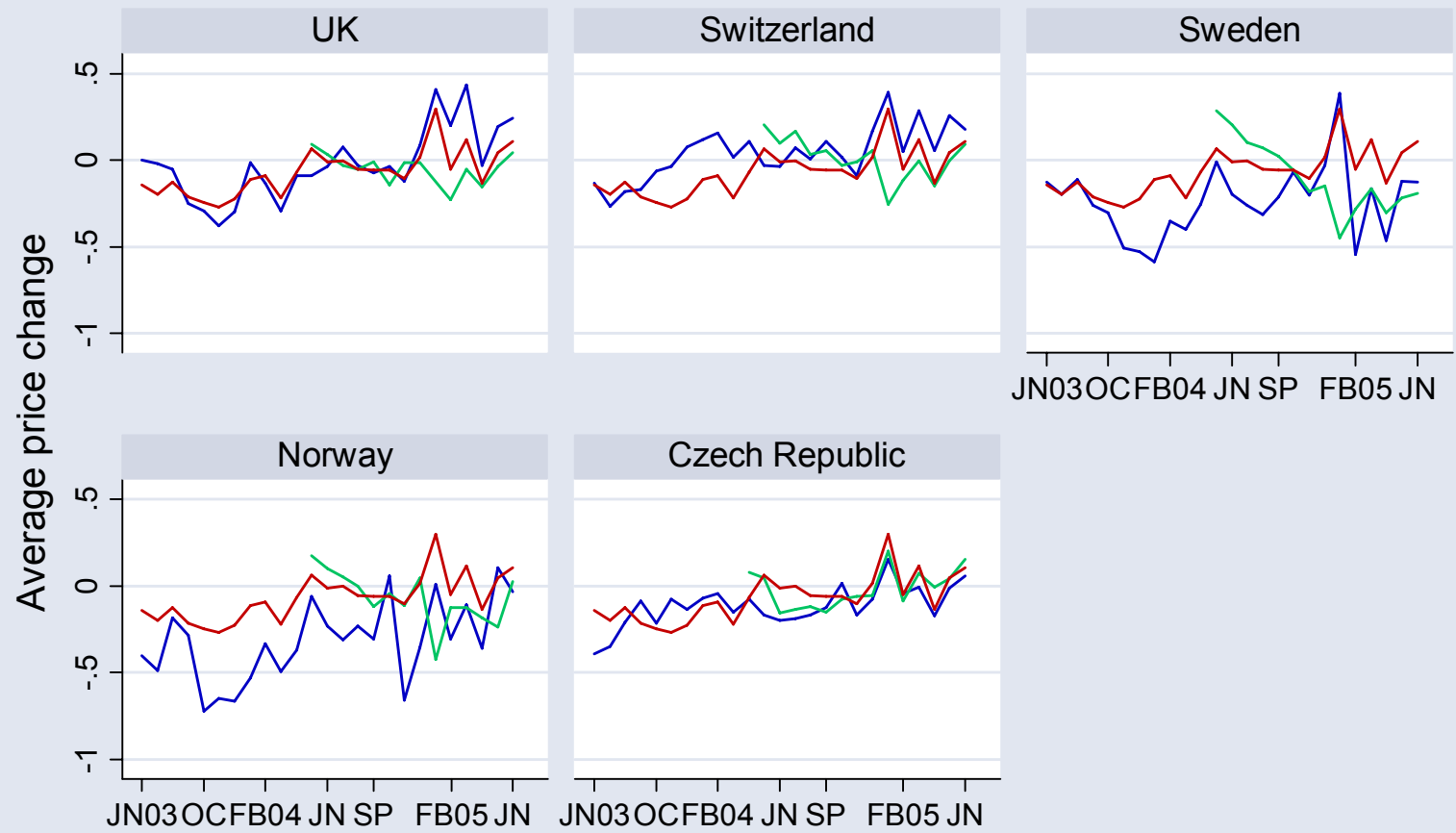

JN03OCFB04 JN SP FB05 JN

N03OCFB04 JN SP FB05 JN

Source: see main text

Mean LC

Mean TC

Mean NoELand

Graphs by nation_noeuro

Source: Our Internet-retrieved fares. 
Figure 1: Evolution of total flights and passengers by geographical location and type of carrier.

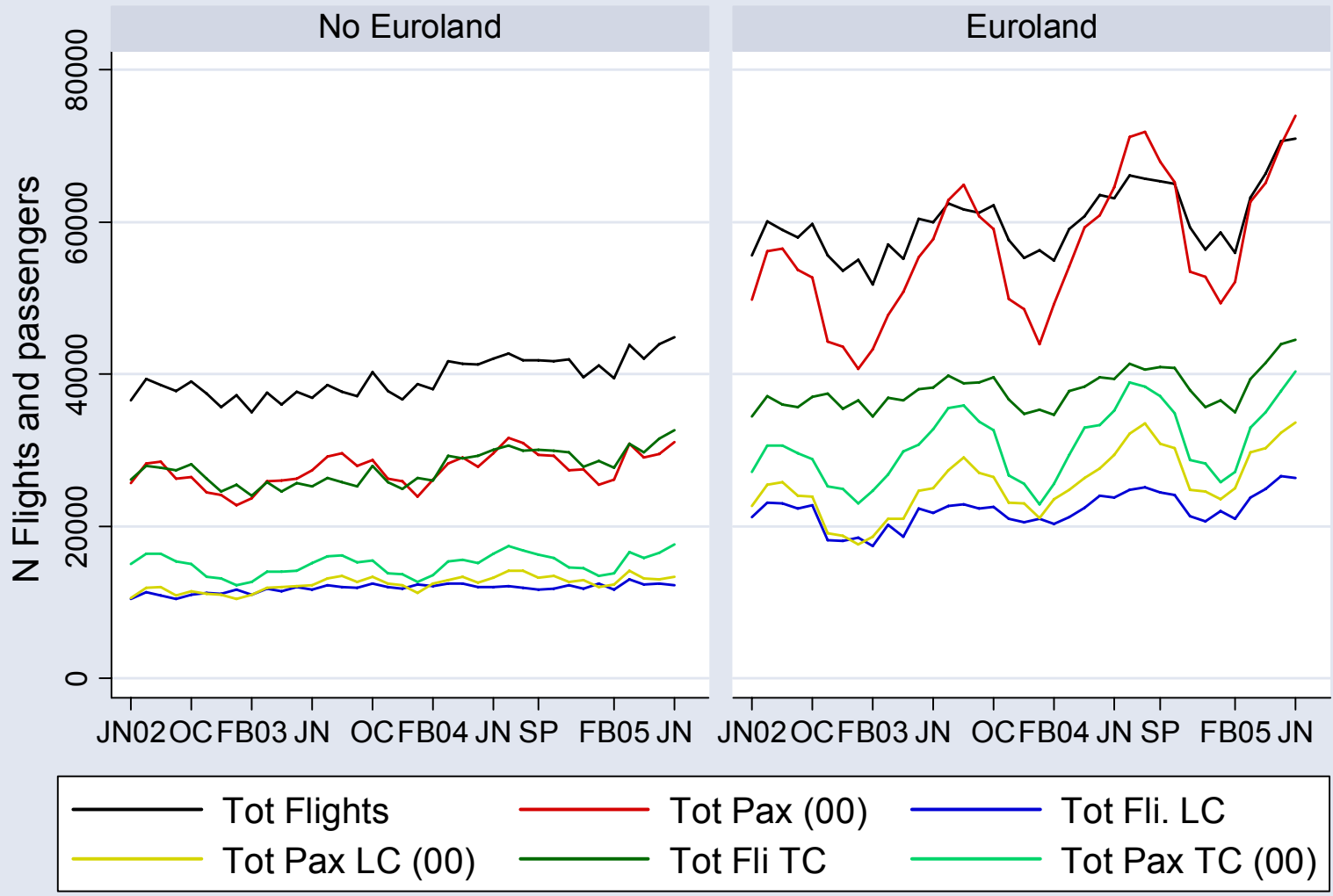

Graphs by euro

Source : CAA. Note: all Tot.Pax divided by 100 . 
TABLE 1 - Average one-way fares by airline and season

\begin{tabular}{|c|c|c|c|c|c|c|c|c|}
\hline & Jun02-Oct02 & Nov02-Mar03 & Apr03-Oct03 & Nov03-Mar04 & Apr04-Oct04 & Nov04-Mar05 & Apr05-Jun05 & Tot.Obs. \\
\hline Bmibaby & & $46.0(21963)$ & $48.9(115201)$ & $29.8(61486)$ & $38.3(160972)$ & $31.2(129706)$ & $40.7(55685)$ & 545013 \\
\hline RYANAIR & $44.9(133127)$ & $30.3(304771)$ & 35.7 (715953) & $25.5(407605)$ & 34.9 (784571) & $23.9(470781)$ & $31.2(500256)$ & 3317064 \\
\hline EASYJET & $47.9(104427)$ & $38.3(316854)$ & $47.7(685381)$ & 33.7 (457398) & $42.7(1022782)$ & $37.3(504738)$ & $48.4(590450)$ & 3682030 \\
\hline BUZZ & $59.0(43198)$ & $33.7(67724)$ & & & & & & 110922 \\
\hline Go Fly & $73.9(74288)$ & $44.6(50988)$ & & & & & & 125276 \\
\hline MyTravelLite & & & & $41.8(12103)$ & $59.1(37382)$ & $36.1(30667)$ & $57.2(19708)$ & 99860 \\
\hline Aer Lingus & & & 56.5 (31008) & $53.2(15437)$ & $59.1(26765)$ & 99.5 (56791) & $103.4(17336)$ & 147337 \\
\hline Air Europa & & & $51.7(2147)$ & $54.1(811)$ & 96.6 (1947) & $94.1(16356)$ & $86.5(4867)$ & 26128 \\
\hline Alitalia & & & $75.2(11308)$ & $68.1(10138)$ & $91.3(29633)$ & 74.6 (42798) & $82.2(14129)$ & 108006 \\
\hline BMI BritiMidland & & & $54.3(64187)$ & $51.7(49858)$ & $57.4(147038)$ & $55.5(143308)$ & 58.7 (48109) & 452500 \\
\hline British Airways & & & $70.8(136088)$ & $69.3(89712)$ & $76.5(286210)$ & 77.7 (333628) & $79.2(110520)$ & 956158 \\
\hline Czech Airlines & & & $86.8(1701)$ & $71.6(1687)$ & $78.5(8343)$ & $73.5(15318)$ & $82.0(5084)$ & 32133 \\
\hline Iberia & & & $91.3(15976)$ & $77.1(11892)$ & $101.9(36503)$ & $67.8(47611)$ & 72.7 (15855) & 127837 \\
\hline KLM & & & $70.8(14553)$ & $73.3(8782)$ & $82.3(22030)$ & $85.2(21189)$ & $64.0(7031)$ & 73585 \\
\hline Lufthansa & & & $62.5(19426)$ & $66.5(12551)$ & $72.9(47498)$ & 57.7 (39913) & $59.7(13256)$ & 132644 \\
\hline Scandin. Airlines & & & $69.0(12982)$ & $82.8(10262)$ & $72.7(30943)$ & $69.8(40141)$ & 66.7 (13569) & 107897 \\
\hline Tot.Obs. & 355040 & 762300 & 1856325 & 1166445 & 2697161 & 1955017 & 1436448 & 10228736 \\
\hline
\end{tabular}

Source: our calculations based on the Internet retrieved fares. (Number of observations used to calculate the average is in parentheses). 
Table 2 - Percentage fare changes by days of query prior to departure, season and geographical location

\begin{tabular}{|c|c|c|c|c|c|c|c|c|c|c|}
\hline & \multicolumn{2}{|c|}{ Jun03-Oct03 } & \multicolumn{2}{|c|}{ Nov03-Mar04 } & \multicolumn{2}{|c|}{ Apr04-Oct04 } & \multicolumn{2}{|c|}{ Nov04-Mar05 } & \multicolumn{2}{|c|}{ Apr05-Jun05 } \\
\hline Days & $\begin{array}{l}\text { No } \\
\text { Eland }\end{array}$ & Eland & $\begin{array}{l}\text { No } \\
\text { Eland }\end{array}$ & Eland & $\begin{array}{l}\text { No } \\
\text { Eland }\end{array}$ & Eland & $\begin{array}{l}\text { No } \\
\text { Eland }\end{array}$ & Eland & $\begin{array}{l}\text { No } \\
\text { Eland }\end{array}$ & Eland \\
\hline & \multicolumn{10}{|c|}{$\% \Delta$ Mean Monthly price } \\
\hline $1-4$ & 10.2 & 1.1 & 2.2 & -0.3 & -3.2 & 2.4 & 7.1 & 5.8 & 8.4 & -5.6 \\
\hline $7-10$ & -17.0 & -31.6 & -12.5 & -22.7 & 1.8 & 5.9 & 6.0 & 11.1 & 5.0 & -7.1 \\
\hline $14-21$ & -32.3 & -40.7 & -26.1 & -36.5 & 0.0 & 0.5 & 8.5 & 9.6 & 3.8 & -8.1 \\
\hline $28-35$ & -27.2 & -30.5 & -27.8 & -33.2 & -3.4 & -5.9 & 6.5 & 6.5 & -2.5 & -8.1 \\
\hline $42-49$ & -29.6 & -23.5 & -23.9 & -28.4 & -5.3 & -10.2 & 3.5 & 0.3 & 0.4 & -4.9 \\
\hline $56-70$ & -22.9 & -17.6 & -38.6 & -31.1 & -16.6 & -19.8 & -2.1 & -8.5 & 5.1 & -10.1 \\
\hline & \multicolumn{10}{|c|}{$\% \Delta$ Median Monthly price } \\
\hline $1-4$ & 10.1 & 1.6 & 0.7 & -0.6 & -2.8 & 3.6 & 4.2 & 2.1 & 5.8 & -9.4 \\
\hline $7-10$ & -20.8 & -41.4 & -17.2 & -35.3 & 1.5 & 7.0 & -1.3 & 7.9 & 1.7 & -8.4 \\
\hline $14-21$ & -40.6 & -51.5 & -35.6 & -56.0 & $\begin{array}{l}-1.4 \\
\end{array}$ & 1.0 & 8.5 & 6.7 & $\begin{array}{l}-1.3 \\
\end{array}$ & -11.1 \\
\hline $28-35$ & -38.0 & -37.6 & -40.6 & -51.8 & -4.8 & -7.0 & 12.0 & 8.9 & -5.2 & -10.9 \\
\hline $42-49$ & -36.3 & -26.7 & -33.3 & -39.6 & -8.3 & -11.0 & 7.1 & -1.7 & 0.5 & -9.0 \\
\hline $56-70$ & -25.3 & -21.1 & -49.5 & -40.7 & -20.6 & -21.9 & -1.4 & -21.8 & 5.5 & -11.3 \\
\hline & \multicolumn{10}{|c|}{$\% \Delta$ Minimum Monthly price } \\
\hline $1-4$ & 25.5 & 4.1 & 2.9 & 9.0 & 3.3 & 15.8 & 12.9 & 18.6 & 11.8 & -2.1 \\
\hline $7-10$ & -35.5 & -79.9 & -71.7 & -125.5 & 16.2 & 30.9 & 12.2 & 25.2 & 3.6 & 2.8 \\
\hline $14-21$ & -72.5 & -100.4 & -85.1 & -101.5 & -8.8 & -8.6 & 16.7 & 8.9 & -2.0 & -1.0 \\
\hline $28-35$ & -57.6 & -78.4 & -109.4 & -137.1 & -13.6 & -20.7 & 29.5 & 31.0 & -5.5 & -8.4 \\
\hline $42-49$ & -44.7 & -66.2 & -97.9 & -94.4 & -20.3 & -23.2 & 16.6 & 2.3 & 14.3 & 1.0 \\
\hline $56-70$ & -25.7 & -51.7 & -88.3 & -86.5 & -33.7 & -49.7 & 30.3 & -6.5 & 40.3 & 19.7 \\
\hline
\end{tabular}

Source: our elaboration on the Internet-retrieved fares' dataset. 
Table 3 - Samples composition by period and number of companies per route

\begin{tabular}{|c|c|c|c|c|c|c|c|c|c|}
\hline & \multicolumn{3}{|c|}{ Route with one airline (\%) } & \multicolumn{3}{|c|}{ Route with two airlines (\%) } & \multicolumn{3}{|c|}{ Route with 3 or more airlines (\%) } \\
\hline Samples & CAA & Internet & Estimation & CAA & Internet & Estimation & CAA & Internet & Estimation \\
\hline Jun 03 & $438(78.5)$ & $131(69.7)$ & $58(87.9)$ & $99(17.7)$ & $45(23.9)$ & $7(10.6)$ & $21(3.8)$ & $12(6.4)$ & $1(1.5)$ \\
\hline Jul 03 & $443(79.4)$ & $132(70.2)$ & $65(86.7)$ & $96(17.2)$ & $44(23.4)$ & $8(10.7)$ & $19(3.4)$ & $12(6.4)$ & $2(2.7)$ \\
\hline Aug 03 & $432(77.8)$ & $153(70.8)$ & $64(84.2)$ & $107(19.3)$ & $51(23.6)$ & $10(13.2)$ & $16(2.9)$ & $12(5.6)$ & $2(2.6)$ \\
\hline Sept 03 & $441(78.8)$ & $164(74.2)$ & $82(82.8)$ & $103(18.4)$ & $48(21.7)$ & $14(14.1)$ & $16(2.9)$ & $9(4.1)$ & $3(3.0)$ \\
\hline Oct 03 & 446 (77.3) & $162(72.0)$ & $81(82.7)$ & $112(19.4)$ & $49(21.8)$ & $14(14.3)$ & $19(3.3)$ & $14(6.2)$ & $3(3.1)$ \\
\hline Nov 03 & $434(78.3)$ & $160(72.4)$ & $82(82.8)$ & 101 (18.2) & $46(20.8)$ & $14(14.1)$ & $19(3.4)$ & $15(6.8)$ & $3(3.0)$ \\
\hline Dec 03 & $447(78.3)$ & $163(70.9)$ & $80(80.8)$ & $105(18.4)$ & $53(23.0)$ & $16(16.2)$ & $19(3.3)$ & $14(6.1)$ & $3(3.0)$ \\
\hline Jan 04 & $453(78.2)$ & $162(71.7)$ & $86(76.8)$ & 107 (18.5) & $52(23.0)$ & $21(18.8)$ & $19(3.3)$ & $12(5.3)$ & $5(4.5)$ \\
\hline Feb 04 & 446 (78.2) & $163(70.3)$ & $88(75.9)$ & 105 (18.4) & $55(23.7)$ & $23(19.8)$ & $19(3.3)$ & $14(6.0)$ & $5(4.3)$ \\
\hline Mar 04 & $461(78.1)$ & $165(70.8)$ & $90(76.3)$ & $105(17.8)$ & $52(22.3)$ & $22(18.6)$ & $24(4.1)$ & $16(6.9)$ & $6(5.1)$ \\
\hline Apr 04 & $485(78.2)$ & 169 (71.9) & $95(68.8)$ & $110(17.7)$ & $51(21.7)$ & $32(23.2)$ & $25(4.0)$ & $15(6.4)$ & $11(8.0)$ \\
\hline May 04 & $498(78.8)$ & $164(72.6)$ & 113( & $111(17.6)$ & $49(21.7)$ & $44(26.0)$ & $23(3.6)$ & $13(5.8)$ & $12(7.1)$ \\
\hline Jun 04 & $504(78.9)$ & $164(71.0)$ & $111(66.9)$ & $106(16.6)$ & $50(21.6)$ & $40(24.1)$ & $29(4.5)$ & $17(7.4)$ & $15(9.0)$ \\
\hline Jul 04 & $518(79.1)$ & $163(72.1)$ & $112(67.9)$ & 109 (16.6) & $47(20.8)$ & $40(24.2)$ & $28(4.3)$ & $16(7.1)$ & $13(7.9)$ \\
\hline Aug 04 & $515(79.0)$ & $166(71.9)$ & $137(70.6)$ & 111 & $49(21.2)$ & $43(22.2)$ & $26(4.0)$ & 16 & $14(7.2)$ \\
\hline Sept 04 & $528(79.3)$ & 188 (74.3) & $145(71.4)$ & $112(16.8)$ & $48(19.0)$ & $44(21.7)$ & $26(3.9)$ & $17(6.7)$ & $14(6.9)$ \\
\hline Oct 04 & $532(80.0)$ & $194(74.0)$ & 146 (71.9) & $109(16.4)$ & $52(19.8)$ & $46(22.7)$ & $24(3.6)$ & $16(6.1)$ & $11(5.4)$ \\
\hline Nov 04 & $510(79.6)$ & $192(74.1)$ & $146(73.0)$ & 111 (17.3) & $51(19.7)$ & $43(21.5)$ & 20( & $16(6.2)$ & $11(5.5)$ \\
\hline Dec 04 & 510 (79.3) & $192(75.3)$ & $145(71.1)$ & $112(17.4)$ & $52(20.4)$ & $48(23.5)$ & $21(3.3)$ & $11(4.3)$ & $11(5.4)$ \\
\hline Jan 05 & $524(78.8)$ & $195(71.2)$ & $142(71.7)$ & $121(18.2)$ & $67(24.5)$ & $46(23.2)$ & $20(3.0)$ & $12(4.4)$ & $10(5.1)$ \\
\hline Feb 05 & $528(78.6)$ & 194 (71.3) & 142 (69.3) & $120(17.9)$ & $64(23.5)$ & $51(24.9)$ & $24(3.6)$ & $14(5.1)$ & $12(5.9)$ \\
\hline Mar 05 & $554(77.5)$ & $193(70.2)$ & $140(68.3)$ & 131 (18.3) & $64(23.3)$ & $48(23.4)$ & $30(4.2)$ & $18(6.5)$ & $17(8.3)$ \\
\hline Apr 05 & $584(78.9)$ & $203(71.5)$ & $144(68.9)$ & 131 (17.7) & $63(22.2)$ & $50(23.9)$ & $25(3.4)$ & $18(6.3)$ & $15(7.2)$ \\
\hline May 05 & $591(78.2)$ & $208(72.0)$ & $145(69.0)$ & $138(18.3)$ & $62(21.5)$ & $48(22.9)$ & $27(3.6)$ & $19(6.6)$ & $17(8.1)$ \\
\hline Jun 05 & 601 (77.6) & $200(70.7)$ & $137(66.8)$ & $145(18.7)$ & $63(22.3)$ & 49 (23.9) & $28(3.6)$ & $20(7.1)$ & $19(9.3)$ \\
\hline
\end{tabular}

Source: our calculations based on United Kingdom Civil Aviation Authority data (CAA), on Internet-retrieved fares Data (Internet) and the resulting Estimation sample. 
Table 4- Descriptive statistics of regressors by season.

\begin{tabular}{|c|c|c|c|c|c|c|c|c|c|c|}
\hline & \multicolumn{2}{|c|}{$\begin{array}{l}\text { Jun03-Oct03 } \\
\mathrm{N}=2095\end{array}$} & \multicolumn{2}{|c|}{$\begin{array}{l}\text { Nov03-Mar04 } \\
\mathrm{N}=2837\end{array}$} & \multicolumn{2}{|c|}{$\begin{array}{l}\text { Apr04-Oct04 } \\
\mathrm{N}=8429\end{array}$} & \multicolumn{2}{|c|}{$\begin{array}{l}\text { Nov04-Mar05 } \\
\mathrm{N}=6206\end{array}$} & \multicolumn{2}{|c|}{$\begin{array}{l}\text { Apr05-Jun05 } \\
\mathrm{N}=4231\end{array}$} \\
\hline & Mean & $\mathrm{SE}$ & Mean & $\mathrm{SE}$ & Mean & SE & Mean & $\mathrm{SE}$ & Mean & $\mathrm{SE}$ \\
\hline$\% \Delta$ Exchange rate & -8.76 & 0.03 & -5.00 & 0.04 & 3.77 & 0.02 & -0.50 & 0.02 & -2.35 & 0.02 \\
\hline$\% \Delta$ Exchg ${ }^{*} \mathrm{D}$ Eland & -7.95 & 0.04 & -4.78 & 0.04 & 3.15 & 0.02 & -0.17 & 0.01 & -1.81 & 0.01 \\
\hline$\% \Delta$ Fuel Cost & -8.16 & 0.06 & -10.0 & 0.13 & 38.8 & 0.12 & 35.1 & 0.09 & 36.2 & 0.08 \\
\hline Inflation rate & 0.023 & 0.73 & 0.021 & 0.61 & 0.023 & 0.71 & 0.022 & 0.72 & 0.022 & 0.73 \\
\hline Inflation * D_Eland & 0.020 & 1.13 & 0.018 & 0.98 & 0.019 & 1.21 & 0.018 & 1.25 & 0.017 & 1.21 \\
\hline Citypair Size & 0.12 & 0.13 & 0.09 & 0.11 & 0.12 & 0.15 & 0.11 & 0.15 & 0.11 & 0.15 \\
\hline $\begin{array}{l}\mathrm{N} \text { departures for } \\
\text { arrival }\end{array}$ & 2.81 & 2.53 & 4.03 & 3.73 & 4.51 & 4.14 & 4.29 & 3.99 & 4.59 & 4.32 \\
\hline $\begin{array}{l}\mathrm{N} \text { routes airline in } \\
\text { market }\end{array}$ & 1.76 & 1.03 & 1.65 & 0.92 & 1.76 & 1.01 & 1.78 & 1.03 & 1.86 & 1.10 \\
\hline $\begin{array}{l}\text { D_Own Entry in } \\
\text { route }\end{array}$ & 0.00 & 0.00 & 0.004 & 0.06 & 0.02 & 0.14 & 0.01 & 0.09 & 0.00 & 0.00 \\
\hline Route $\mathrm{HHI}$ & 0.92 & 0.18 & 0.89 & 0.20 & 0.80 & 0.25 & 0.80 & 0.25 & 0.79 & 0.25 \\
\hline $\begin{array}{l}\text { D_Departure is a } \\
\text { hub }\end{array}$ & 0.83 & 0.37 & 0.64 & 0.48 & 0.63 & 0.48 & 0.63 & 0.48 & 0.62 & 0.49 \\
\hline
\end{tabular}

Source: Datastream for Inflation and Exchange rate data; U.S. Department of Energy for Jet-Fuel data (excel file: PSW14VDJT.xls); UK Civil Aviation Authority for the remainder variables. D_ denote a Dummy variable.

Exchange rates are measured in term of currency per UK sterling: a negative value reflects a devaluation of the latter. 
Table 5 - Panel Estimates with groups defined by company, route and days from departure. Model 1.

Dependent Variable: $\% \Delta$ Mean Monthly price. t-statistics in round brackets

\begin{tabular}{|c|c|c|c|c|}
\hline & $\begin{array}{l}\text { HT RE IV: } \\
\text { Full Sample }\end{array}$ & $\begin{array}{l}2 \text { stage FE: } \\
\text { Full Sample }\end{array}$ & $\begin{array}{l}\text { HT RE IV: } \\
\text { LCC Sample }\end{array}$ & $\begin{array}{l}2 \text { stage FE: } \\
\text { LCC Sample }\end{array}$ \\
\hline D_Season4: Nov03-Mar04 & $-0.03(1.23)$ & $-0.03(1.56)$ & $-0.03(1.18)$ & $-0.03(1.18)$ \\
\hline D_Season5: Apr04-Oct04 & $0.06(2.26)^{6}$ & $0.06(2.25)^{6}$ & $-0.03(0.98)$ & $-0.03(0.98)$ \\
\hline D_Season6: Nov04-Mar05 & $0.21(7.34)^{\mathrm{a}}$ & $0.20(6.70)^{\mathrm{a}}$ & $0.23(7.43)^{\mathrm{a}}$ & $0.22(7.43)^{a}$ \\
\hline D_Season7: Apr05-Jun05 & $0.49(15.5)^{\mathrm{a}}$ & $0.47(15.5)^{\mathrm{a}}$ & $0.58(16.6)^{a}$ & $0.56(16.6)^{\mathrm{a}}$ \\
\hline$\% \Delta$ Exchng rate Seas $3 / 4$ & $-0.66(3.07)^{\mathrm{a}}$ & $-0.75(3.42)^{\mathrm{a}}$ & $-0.63(2.83)^{\mathrm{a}}$ & $-0.72(2.83)^{\mathrm{a}}$ \\
\hline$\% \Delta$ Exchng rate Seas $5 / 6 / 7$ & $0.11(0.78)$ & $0.08(0.64)$ & $-0.15(0.90)$ & $-0.23(0.90)$ \\
\hline$\% \Delta$ Fuel Cost ${ }^{\dagger}$ & $0.44(3.93)^{\mathrm{a}}$ & $0.46(3.74)^{\mathrm{a}}$ & $0.44(3.83)^{\mathrm{a}}$ & $0.46(3.83)^{\mathrm{a}}$ \\
\hline Distance $10^{\wedge} 3 \mathrm{ml}$ & $-0.05(1.18)$ & $-0.06(0.94)$ & $-0.03(0.67)$ & $-0.07(0.67)$ \\
\hline Inflation rate & $4.55(4.24)^{\mathrm{a}}$ & $4.75(4.72)^{a}$ & $4.53(3.83)^{a}$ & $(3.83)^{\mathrm{a}}$ \\
\hline Inflation * D_Eurc & $-8.10(6.30)^{\mathrm{a}}$ & $-8.34(6.43)^{\mathrm{a}}$ & $-8.59(6.11)^{\mathrm{a}}$ & $-8.80(6.11)^{\mathrm{a}}$ \\
\hline $\mathrm{N}$ departures airline to arrival & $-0.00(1.54)$ & $-0.00(0.64)$ & $-0.01(3.33)^{\mathrm{a}}$ & $(3.33)^{\mathrm{a}}$ \\
\hline $\mathrm{N}$ routes of airline in citypair & $-0.04(6.82)^{a}$ & $-0.07(8.14)^{\mathrm{a}}$ & $-0.04(5.48)^{\mathrm{a}}$ & $(5.48)^{\mathrm{a}}$ \\
\hline D_Own Entry in route & $0.11(4.56)^{\mathrm{a}}$ & $0.11(3.31)^{\mathrm{a}}$ & $0.16(5.81)^{\mathrm{a}}$ & $0.16(5.81)^{\mathrm{a}}$ \\
\hline D_Buzz 1 yr post takeover & $-0.07(2.81)^{\mathrm{a}}$ & $-0.05(1.20)$ & $-0.07(2.63)^{b}$ & $-0.05(2.63)$ \\
\hline D_Buzz 2 yrs post takeover & $0.10(4.04)^{\mathrm{a}}$ & $0.12(3.18)^{a}$ & $0.10(3.83)^{\mathrm{a}}$ & $(3.83)^{\mathrm{a}}$ \\
\hline D_Gofl & $-0.16(10.5)^{\mathrm{a}}$ & $-0.15(9.96)^{\mathrm{a}}$ & $-0.16(10.3)^{a}$ & $(10.3)^{a}$ \\
\hline D_Gofl & $-0.01(0.91)$ & $(0.49)$ & $-0.01(0.97)$ & $1(0.97)$ \\
\hline Citypai & $1.30(11.6)^{\mathrm{a}}$ & $(10.7)^{\mathrm{a}}$ & $1.18(10.2)^{a}$ & $(10.2)^{a}$ \\
\hline Route Herfindhal Index & $0.14(3.90)^{\mathrm{a}}$ & $0.17(4.50)^{\mathrm{a}}$ & $0.14(3.44)^{a}$ & $0.17(3.44)^{\mathrm{a}}$ \\
\hline D_Season4 * D_Eurozone & $-0.02(0.81)$ & $-0.01(0.33)$ & $-0.02(0.91)$ & $-0.01(0.91)$ \\
\hline D_Season5 ${ }^{2}$ D_Eurozone & $0.05(2.22)^{6}$ & $0.08(3.36)^{a}$ & $0.09(3.53)^{a}$ & $0.12(3.53)^{\mathrm{a}}$ \\
\hline${ }^{*}$ D_Eur & $0.07(2.93)^{\mathrm{a}}$ & $0.10(3.72)^{\mathrm{a}}$ & $0.05(1.77)^{\mathrm{c}}$ & $(1.77)^{\mathrm{C}}$ \\
\hline D_Seaso & $-0.01(0.57)$ & $(0.57)$ & $-0.05(2.02)^{b}$ & $1(2.02)$ \\
\hline D_ltaly ${ }^{\mp}$ & $0.04(0.98)$ & $(0.28)$ & $0.08(1.59)$ & $0(1.59)$ \\
\hline D_France ${ }^{\ddagger}$ & $0.07(1.70)$ & $0.01(0.31)$ & $0.10(2.34)^{b}$ & $0.04(2.34)^{6}$ \\
\hline D_Spain ${ }^{\ddagger}$ & $0.13(2.78)^{6}$ & $0.11(2.25)^{b}$ & $0.16(2.95)^{a}$ & $0.17(2.95)^{\mathrm{a}}$ \\
\hline D Holland ${ }^{\mp}$ & $-0.05(0.92)$ & $-0.11(2.17)^{b}$ & $-0.02(0.28)$ & $-0.10(0.28)$ \\
\hline D_Gerr & $-0.08(1.79)^{c}$ & $-0.15(2.97)^{\mathrm{a}}$ & $0.00(0.06)$ & $4(0.06)$ \\
\hline D_Belgium ${ }^{+}$ & $0.02(0.56)$ & $(1.08)$ & $0.03(0.63)$ & $(0.63)$ \\
\hline D Greece ${ }^{\mp}$ & $-0.43(6.63)^{a}$ & $-0.56(5.08)^{\mathrm{a}}$ & $-0.43(5.65)^{\mathrm{a}}$ & $-0.56(5.65)^{\mathrm{a}}$ \\
\hline D_Ireland ${ }^{\ddagger}$ & $-0.97(7.18)^{\mathrm{a}}$ & $-1.24(14.4)^{\mathrm{a}}$ & $-0.83(5.51)^{\mathrm{a}}$ & $-1.19(5.51)^{\mathrm{a}}$ \\
\hline D_Portugal ${ }^{\mp}$ & $0.04(0.84)$ & $0.00(0.06)$ & $0.12(2.51)^{\mathrm{b}}$ & $0.20(2.51)^{\mathrm{b}}$ \\
\hline D_Switzerland ${ }^{\ddagger}$ & $-0.03(0.48)$ & $-0.07(0.76)$ & $0.01(0.10)$ & $-0.02(0.10)$ \\
\hline D_Sweden ${ }^{\ddagger}$ & $-0.25(7.08)^{a}$ & $-0.31(7.15)^{\mathrm{a}}$ & $-0.21(5.05)^{\mathrm{a}}$ & $-0.30(5.05)^{\mathrm{a}}$ \\
\hline D_Nory & $-0.37(7.95)^{\mathrm{a}}$ & $-0.46(4.06)^{\mathrm{a}}$ & $-0.31(5.94)^{\mathrm{a}}$ & $-0.39(5.94)^{\mathrm{a}}$ \\
\hline D Austria ${ }^{\mp}$ & $-0.43(8.02)^{\mathrm{a}}$ & $(5.43)^{a}$ & $-0.35(5.26)^{a}$ & $-0.42(5.26)^{\mathrm{a}}$ \\
\hline Republic $^{\ddagger}$ & $-0.27(6.72)^{\mathrm{a}}$ & $(5.18)^{\mathrm{a}}$ & $-0.25(5.72)^{a}$ & $-0.30(5.72)^{\mathrm{a}}$ \\
\hline D_7-10 days prior departure ${ }^{\mp}$ & $-0.05(3.30)^{\mathrm{a}}$ & $-0.05(3.53)^{\mathrm{a}}$ & $-0.02(1.21)$ & $-0.01(1.21)$ \\
\hline D_14-21 days prior depart. ${ }^{\ddagger}$ & $-0.09(5.18)^{\mathrm{a}}$ & $-0.06(4.69)^{\mathrm{a}}$ & $-0.08(4.36)^{a}$ & $-0.06(4.36)^{a}$ \\
\hline D_28-35 days prior depart. ${ }^{\ddagger}$ & $-0.10(6.15)^{\mathrm{a}}$ & $-0.08(5.89)^{\mathrm{a}}$ & $-0.12(6.19)^{a}$ & $-0.10(6.19)^{\mathrm{a}}$ \\
\hline D_42-49 days prior depart. ${ }^{\mp}$ & $-0.12(6.96)^{\mathrm{a}}$ & $-0.10(6.72)^{\mathrm{a}}$ & $-0.14(7.19)^{\mathrm{a}}$ & $-0.12(7.19)^{\mathrm{a}}$ \\
\hline D_56-70 days prior depart. ${ }^{\mp}$ & $-0.17(9.30)^{\mathrm{a}}$ & $-0.14(9.10)^{\mathrm{a}}$ & $-0.16(8.71)^{a}$ & $-0.14(8.71)^{\mathrm{a}}$ \\
\hline D Departu & $-0.14(5.08)^{\mathrm{a}}$ & $-0.11(4.22)^{\mathrm{a}}$ & $-0.17(5.81)^{\mathrm{a}}$ & $-0.15(5.81)^{\mathrm{a}}$ \\
\hline Dummy Airlines included? ${ }^{\mp}$ & \multicolumn{2}{|c|}{ Yes, both for LCC and FSC } & \multicolumn{2}{|c|}{ Yes, only LCC } \\
\hline $\mathrm{N}$ & 23798 & 23781 & 18931 & 18924 \\
\hline $\mathrm{N} \mathrm{sec}$ & & 1742 & & 1243 \\
\hline & & 0.102 & & 0.125 \\
\hline $\mathrm{R}^{2}$ second stage & & 0.637 & & 0.611 \\
\hline
\end{tabular}

Note: ${ }^{\mathrm{a}, \mathrm{b}, \mathrm{c}}$ denotes significance at $1 \%, 5 \%$ and $10 \%$ level, respectively. D_ identifies a Dummy variable. Models include a constant. Standard Errors in the FE models are robust to heteroskedasticity and auto-correlation. HT RE IV is the instrumental variable estimator proposed in Hausman and Taylor (1981). ${ }^{\ddagger}$ Based on Oaxaca and Geisler (2003) and Polachek and Kim (1994), the estimates from these time invariant dummies in the FE models are obtained from a second stage OLS estimation with White standard errors clustered over routes. $\dagger$ The coefficients from the interation of this variable with the seasonal dummies not reported to save on space. 
Table 6- Panel Estimates with groups defined by company and route. Model 2.

Dependent Variable: \% $\Delta$ Mean Monthly price.

\begin{tabular}{|c|c|c|c|c|}
\hline & $\begin{array}{l}\text { HT RE IV: } \\
\text { Full Sample }\end{array}$ & $\begin{array}{l}2 \text { stage FE: } \\
\text { Full Sample }\end{array}$ & $\begin{array}{l}\text { HT RE IV: } \\
\text { LCC Sample }\end{array}$ & $\begin{array}{l}2 \text { stage FE: } \\
\text { LCC Sample }\end{array}$ \\
\hline D_Season4: Nov03-Mar04 & $0.14(3.40)^{\mathrm{a}}$ & $0.14(3.52)^{a}$ & $0.14(3.47)^{a}$ & $0.14(3.56)^{\mathrm{a}}$ \\
\hline D_Season5: Apr04-Oct04 & $0.11(2.46)^{b}$ & $0.11(2.66)^{b}$ & $0.05(1.04)$ & $0.05(1.05)$ \\
\hline D_Season6: Nov04-Mar05 & $0.09(1.86)^{\mathrm{c}}$ & $0.10(2.00)^{b}$ & $0.12(2.24)^{b}$ & $0.12(2.25)^{b}$ \\
\hline D_Season7: Apr05-Jun05 & $0.58(10.1)^{\mathrm{a}}$ & $0.58(10.3)^{a}$ & $0.69(11.3)^{\mathrm{a}}$ & $0.69(11.1)^{\mathrm{a}}$ \\
\hline$\% \Delta$ Exchng rate Seas $3 / 4$ & $-0.85(2.18)^{b}$ & $-0.87(2.39)^{b}$ & $-0.86(2.21)^{b}$ & $-0.87(2.38)^{b}$ \\
\hline$\% \Delta$ Exchng rate Seas $5 / 6 / 7$ & $0.51(1.98)^{b}$ & $0.53(2.21)^{b}$ & $0.32(1.08)$ & $0.30(1.14)$ \\
\hline$\% \Delta$ Fuel Cost ${ }^{\dagger}$ & $0.39(1.97)^{\mathrm{b}}$ & $0.39(2.00)^{b}$ & $0.38(1.96)^{6}$ & $0.39(1.99)^{6}$ \\
\hline Distance $10^{\wedge} 3 \mathrm{ml}$ & $-0.04(0.50)$ & $-0.06(0.82)$ & $0.04(0.37)$ & $0.01(0.13)$ \\
\hline Inflation rate & $4.66(2.44)^{6}$ & $4.61(2.36)^{6}$ & $4.09(2.03)^{6}$ & $4.13(1.95)^{\mathrm{C}}$ \\
\hline Inflation * D_Eurozone & $-4.09(1.79)^{\mathrm{C}}$ & $-4.06(1.73)^{c}$ & $-3.98(1.66)$ & $-3.94(1.58)$ \\
\hline $\mathrm{N}$ departures airline to arrival & $-0.00(0.72)$ & $-0.00(0.16)$ & $-0.00(0.84)$ & $-0.01(1.17)$ \\
\hline $\mathrm{N}$ routes of airline in citypair & $-0.04(3.14)^{a}$ & $-0.07(4.67)^{a}$ & $-0.05(4.01)^{a}$ & $-0.08(5.26)^{a}$ \\
\hline D_ Own Entry in route & $0.03(0.73)$ & $0.03(0.52)$ & $0.09(1.78)^{c}$ & $0.09(1.38)$ \\
\hline D_Buzz 1 yr post takeover & $0.05(1.05)$ & $0.08(1.29)$ & $0.06(1.18)$ & $0.08(1.26)$ \\
\hline D Buzz 2 yrs post takeover & $0.09(1.86)^{\mathrm{C}}$ & $0.13(2.12)$ & $0.09(2.01)^{b}$ & $0.13(2.09)^{6}$ \\
\hline D_Gofly 1 yr post takeover & $-0.15(5.69)^{\mathrm{a}}$ & $-0.15(6.03)^{a}$ & $-0.15(5.72)^{a}$ & $-0.15(6.06)^{a}$ \\
\hline D_Gofly 2 yrs $p$ & $-0.01(0.28)$ & $-0.00(0.08)$ & $-0.01(0.21)$ & $0.00(0.05)$ \\
\hline Citypair Size & $1.21(5.86)^{a}$ & $1.33(4.98)^{a}$ & $1.34(6.22)^{a}$ & $1.49(4.78)^{a}$ \\
\hline Route Herfindhal Index & $0.17(2.63)^{b}$ & $0.15(2.48)^{a}$ & $0.16(2.22)^{b}$ & $0.14(2.16)^{b}$ \\
\hline D_Season4 * D_Eurozone & $-0.07(1.60)$ & $-0.06(1.39)$ & $-0.07(1.63)$ & $-0.05(1.37)$ \\
\hline D Season5 * D Eurozone & $0.07(1.57)$ & $0.08(1.93)^{c}$ & $0.10(2.38)^{b}$ & $0.12(2.89)^{\mathrm{a}}$ \\
\hline D_Season6 * D_Eurozone & $0.04(0.86)$ & $4(0.96)$ & $-0.00(0.10)$ & $0.01(0.16)$ \\
\hline D_Season7 ${ }^{*} D$ E_Eurozone & $-0.06(1.29)$ & (1.17) & $-0.08(1.74)^{c}$ & $(1.38)$ \\
\hline D Italy ${ }^{\mp}$ & $0.03(0.36)$ & $(0.02)$ & $0.00(0.00)$ & $-0.03(0.45)$ \\
\hline D_France ${ }^{\ddagger}$ & $0.08(1.04)$ & $0.05(1.16)$ & $0.07(0.81)$ & $0.04(0.83)$ \\
\hline D_Spain ${ }^{\mp}$ & $0.09(0.95)$ & $0.08(1.32)$ & $0.06(0.57)$ & $0.07(0.97)$ \\
\hline D_Holland ${ }^{\ddagger}$ & $-0.01(0.07)$ & $-0.05(1.20)$ & $0.00(0.04)$ & $-0.02(0.37)$ \\
\hline D Germany ${ }^{\ddagger}$ & $0.03(0.30)$ & $-0.03(0.51)$ & $-0.00(0.05)$ & $-0.07(0.95)$ \\
\hline D_Belgium ${ }^{\mp}$ & $-0.37(2.81)^{a}$ & $-0.42(4.73)^{a}$ & $-0.47(3.08)^{a}$ & $-0.52(5.29)^{a}$ \\
\hline D Greece ${ }^{\ddagger}$ & $-0.91(3.46)$ & $-1.03(9.76)^{a}$ & $-1.08(3.67)^{a}$ & $-1.22(11.6)^{a}$ \\
\hline D Ireland ${ }^{\ddagger}$ & $0.04(0.48)$ & $0.01(0.11)$ & $0.08(0.91)$ & $0.11(1.81)^{\mathrm{C}}$ \\
\hline D_Portugal ${ }^{\mp}$ & $-0.01(0.08)$ & $-0.02(0.25)$ & $-0.07(0.51)$ & $-0.08(0.80)$ \\
\hline D_Switzerland ${ }^{\mp}$ & $-0.16(2.18)^{b}$ & $-0.20(3.50)^{a}$ & $-0.18(2.03)^{b}$ & $-0.23(3.46)^{a}$ \\
\hline D Sweden ${ }^{\mp}$ & $-0.30(3.11)^{a}$ & $-0.34(3.16)^{\mathrm{a}}$ & $-0.32(2.98)^{a}$ & $-0.34(2.82)^{\mathrm{a}}$ \\
\hline D_Norway ${ }^{\ddagger}$ & $-0.36(3.15)^{\mathrm{a}}$ & $-0.41(3.49)^{\mathrm{a}}$ & $-0.32(2.28)^{b}$ & $-0.33(2.30)^{6}$ \\
\hline D_Austria ${ }^{\mp}$ & $-0.01(0.05)$ & $-0.04(0.67)$ & $-0.04(0.28)$ & $-0.06(0.97)$ \\
\hline D Czech Republic ${ }^{\ddagger}$ & $-0.14(1.65)$ & $-0.17(2.84)^{a}$ & $-0.20(2.19)^{b}$ & $-0.22(3.35)^{a}$ \\
\hline D_Departure is a hub ${ }^{\mp}$ & $-0.13(2.29)^{6}$ & $-0.10(3.81)^{\mathrm{a}}$ & $-0.12(2.05)^{b}$ & $-0.12(4.23)^{\mathrm{a}}$ \\
\hline Dummy Airlines included? $?^{\mp}$ & \multicolumn{2}{|c|}{ Yes, both for LCC and FSC } & \multicolumn{2}{|c|}{ Yes, only LCC } \\
\hline $\mathrm{N}$ & 4384 & 4382 & 3554 & 3553 \\
\hline $\mathrm{N}$ second stage & & 275 & & 210 \\
\hline$R^{2}$ first stage & & 0.13 & & 0.169 \\
\hline $\mathrm{R}^{2}$ second stage & & 0.622 & & 0.633 \\
\hline
\end{tabular}

Note: ${ }^{\mathrm{a}, \mathrm{b}, \mathrm{c}}$ denotes significance at $1 \%, 5 \%$ and $10 \%$ level, respectively. D_ identifies a Dummy variable. Models include a constant. Standard Errors in the FE models are robust to heteroskedasticity and auto-correlation. HT RE IV is the instrumental variable estimator proposed in Hausman and Taylor (1981). ${ }^{\ddagger}$ Based on Oaxaca and Geisler (2003) and Polachek and Kim (1994), the estimates from these time invariant dummies in the FE models are obtained from a second stage OLS estimation with White standard errors clustered over routes. $\uparrow$ The coefficients from the interation of this variable with the seasonal dummies not reported to save on space. 
Figure 3 - \% difference of fare posted by target firms relative to fares posted by acquiring firms after the takeovers, on routes previously served by the target firms. Fares are distinguished by number of days to departures.

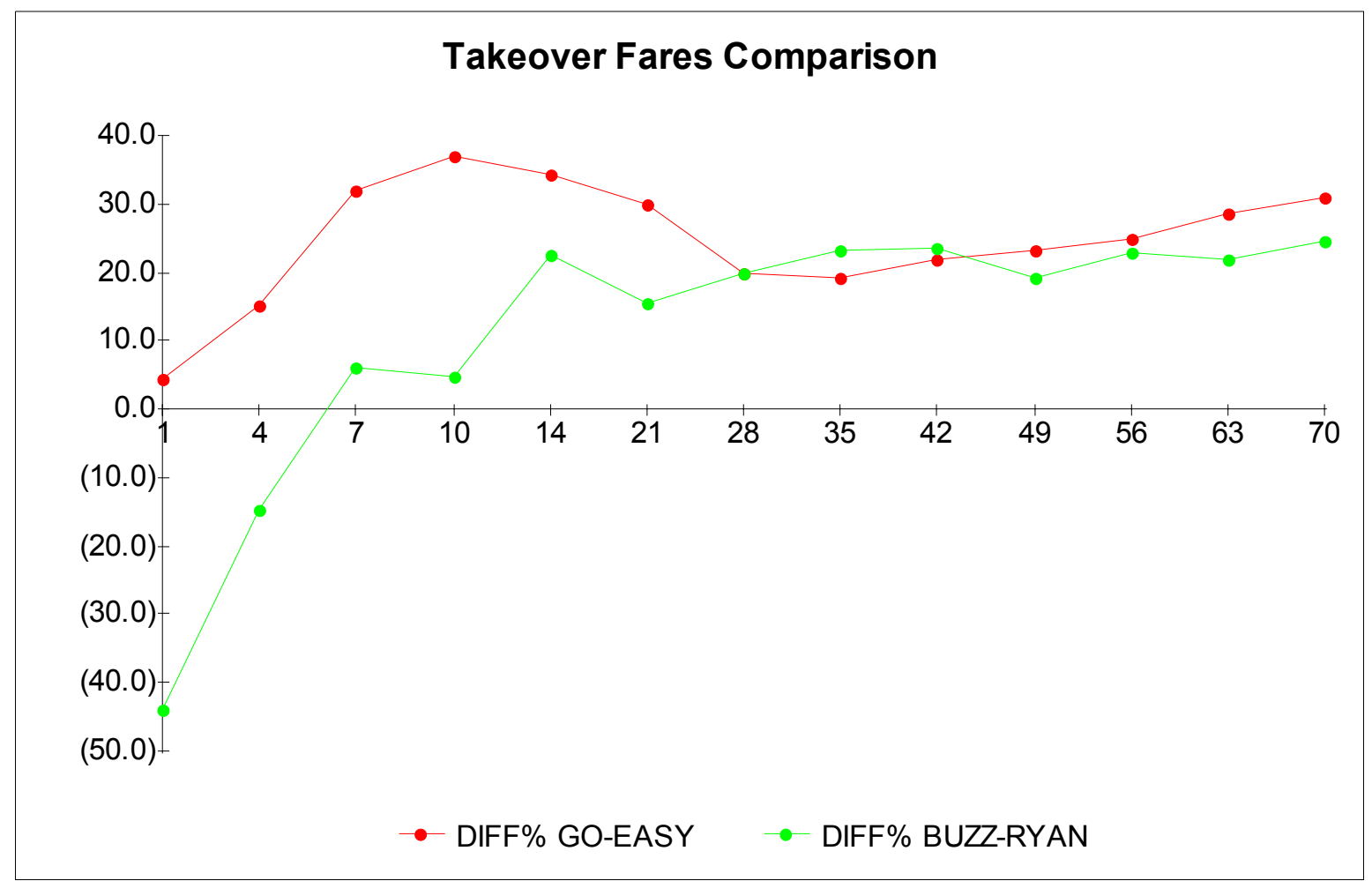

Source: our calculations on the Internet-retrieved dataset of fares. 